\title{
Title: From book to stage to screen: semiotic transformations of Gothic horror genre conventions
}

\author{
Authors: Sabine Tan ${ }^{\mathrm{a}}$, Peter Wignell ${ }^{\mathrm{a}}$, Kay L. O'Halloran ${ }^{\mathrm{a}}$ * \\ ${ }^{a}$ School of Education, Curtin University, Perth, Western Australia \\ *Corresponding author:
}

Associate Professor Kay O’Halloran

School of Education, Faculty of Humanities

Curtin University

Kent Street, Bentley

Western Australia 6102

Email: kay.ohalloran@curtin.edu.au

Bionotes

Sabine Tan is a Research Fellow in the School of Education, Faculty of Humanities at Curtin University. Her research interests include critical multimodal discourse analysis, social semiotics, and visual communication. She is particularly interested in the application of multidisciplinary perspectives within social semiotic theory to the analysis of institutional discourses involving traditional and new media. Email: sabine.tan@curtin.edu.au

Peter Wignell is a Research Fellow in the School of Education, Faculty of Humanities at Curtin University. Peter's current research interests are in Systemic Functional Linguistics, especially in its application to the analysis of multimodal texts. His research has also focused on the role of language in the construction of specialised knowledge. Email: peter.wignell@curtin.edu.au

Kay O'Halloran is Associate Professor in the School of Education, Faculty of Humanities at Curtin University. Her areas of research include multimodal analysis, social semiotics, mathematics discourse, and the development of interactive digital media technologies and visualization techniques for multimodal and sociocultural analytics. Email: kay.ohalloran@curtin.edu.au 


\title{
From book to stage to screen: semiotic transformations of Gothic horror genre conventions
}

\begin{abstract}
This paper adopts a multimodal social semiotic approach for exploring the semiotic changes involved in the transformation of a novel into stage and screen productions. It examines how semiotic resources are deployed in each medium through elements of mise-en-scène, such as speech, music, sound, lighting, props, staging, and cinematographic techniques, and the viewing perspectives that are thus established for audiences. The genre of Gothic horror is selected for this purpose, given how this form of performance has transfixed audiences for centuries and has been adapted for both the stage and the screen. In order to demonstrate how each performance medium has produced its own unique set of foregrounding devices to enthral and captivate audiences, a comparative analysis of excerpts from the novel The Woman in Black by Susan Hill, a videotaped theatrical performance, and the 1989 British television film of the same name, is undertaken. The paper discusses the implications of the multimodal semiotic approach for developing a better understanding of the semiotic transformations that horror genre conventions undergo in different media and the viewership positions that are thus re-drawn for audiences. The paper concludes with a view of multimodal recontextualisation processes which form the underlying basis of human socio-cultural life.
\end{abstract}

Keywords: multimodal; social semiotic; resemiotisation; Gothic horror; The Woman in Black

\section{Introduction}

This paper adopts a multimodal social semiotic approach to exploring the resemiotisations involved in transforming a novel into stage and screen productions. The term 'resemiotisation' was first used by Iedema (2003) to refer to "how meaning shifts from context to context, from practice to practice, or from one stage of a practice to the next" (Iedema 2003, 41). Jewitt $(2014,467)$ summarises Iedema's $(2003)$ use of the term as the phenomenon "in which a particular set of meanings is transformed from one semiotic system (and configuration of media and modes) to another ...”. In the 
process of moving from book, to stage, to screen each new production involves taking meanings encoded in particular ways in one medium and semiotically reconstruing them in a different medium, most typically using the range of resources which become available (e.g. written and spoken language, images, sound, and so forth).

The approach taken to analysing these resemiotisations across different media (in this case, novel, theatre and film) is based on Michael Halliday's (1978) social semiotics, where language and other semiotic resources are viewed as resources for making meaning. Halliday’s social semiotic approach, developed as systemic functional theory (SFT), views semiotic resources as systems of meaning which fulfil a range of functions in human communication. The multimodal social semiotic approach provides the platform for modelling, analysing and interpreting multimodal texts, interactions and events involving language and other resources such as images, sound, embodied action and so forth (e.g. Jewitt, Bezemer, and O'Halloran 2016; O'Halloran, Tan, and Wignell 2016 in press). The analytical approach is demonstrated through examples from the genre of Gothic horror to explore how various combinations of semiotic resources are exploited for creating tension and involving the audience in different media.

The analysis is based on Susan Hill's novel The Woman in Black (1983), which forms the source text for a videotaped theatrical performance by the Main Street Players (2011) based on Stephen Mallatratt's (1989) adaption of the novel for the stage (which is also the second longest-running play in London's West End after Agatha Christie's fabled Mousetrap ${ }^{1}$ ), and the 1989 television film by Britain's ITV network. The narrative of the play and the 1989 TV film follow the novel closely, with only minor variations. Although the plot of the more recent film adaption by Hammer Film Productions (2012) is similar to that of the novel and the play, it contains many 
additional scenes and events which, together with more sophisticated cinematographic effects, function to recontextualise the story further.

The genre of Gothic horror (e.g. Carroll 1990; Cuddon 2013; Prohászková 2012) is selected for analysis as this form has captivated audiences for (literally) centuries. Gothic horror as a distinct literary genre evolved from the eighteenth and nineteenth century Gothic novel, such as the iconic works of Mary Shelley (Frankenstein, 1818) and Bram Stoker (Dracula, 1897). Gothic horror has remained popular throughout its existence and has its own characteristic set of elements, which have remained relatively consistent in different media (Cuddon 2013, 308-309).

The principal allure of Gothic horror stories is the building, release and rebuilding of tension through the creation of uncertainty, mystery, suspense, fright, and shock (e.g. Bordwell 2013; Brophy 1986; Keisner 2008; Waller 1985). Gothic horror stories, plays and films have sets of identifiable features: for example, they are typically set in remote, inhospitable, desolate locations where people are at their most vulnerable; the atmosphere is almost always dark, shadowy or foggy; decaying large old houses and cemeteries are often featured; often sinister children do terrible things or terrible things happen to innocent children; ghosts and other supernatural beings, such as vampires, are often featured; revenge is often a motivating force, and events such as murder, and madness are common (Cuddon 2013, 308-309).

The main aim of Gothic horror tales is "to chill the spine and curdle the blood" (Cuddon 2013, 308). In a novel or short story this is realised through written language. In stage and film productions, semiotic resources such as spoken language, sound and lighting are used for the same purpose. In film, camera techniques such as point of view shots, close-ups and framing through windows and mirrors are also used (e.g. Hantke 2004; Sipos 2010). Gothic horror is an ideal literary and film genre for 
examining how semiotic resources are deployed for creating tension and suspense in different media, because the aim is basically the same, regardless of the platform. In this paper, a multimodal social semiotic approach provides the platform for modelling, analysing and interpreting the resemiotisations across three different media: the 1983 novel, the videotaped theatrical performance (2011), and the 1989 TV film.

\section{The Woman in Black: Plot synopsis and Gothic horror genre conventions}

Susan Hill's novel (1983) forms the prime source for the adaptation of the stage play and the film analysed below. Therefore, the plot and conventions of the genre are discussed to provide a context for the resemiotisation of the story in the other two media.

Set in the early 1900s, The Woman in Black chronicles the story of Arthur Kipps, a young solicitor, who is sent to Crythin Gifford, a small village in a remote part of the east coast of England, to attend the funeral and settle the estate of Mrs Alice Drablow, an old woman who had lived and died alone in an isolated, large, old and decaying house named Eel Marsh House. At the funeral, he sees a young woman with a wasted face, dressed all in black. Unaware of the tragic circumstances that connect the Woman in Black to Mrs Drablow, Arthur sets about his business at Eel Marsh House. There, he sees her again, and in some documents finds clues to the identity of the Woman in Black and her story. He learns that the woman was Mrs Drablow's younger sister, who had a child out of wedlock, and was forced to give up the boy, Nathaniel, for adoption by the Drablows. While in Mrs Drablow's care, the child later drowned in the marshes in an accident involving a pony and trap. After several eerie encounters in the marshes and at Eel Marsh House, Arthur starts to suspect that he might be dealing with a supernatural force. 
The Woman in Black is an example of what Carroll (1990) refers to as “equivocal Gothic horror" which features malevolent supernatural beings and forces, but their authenticity is ambiguous because the stories also contain leading characters whose mental stability is open to question (Carroll 1990,4). The novel's style is that of a nineteenth century Gothic horror novel. The novel features a number of intertextual connections to nineteenth century Gothic horror literature, such as Henry James' classic Gothic horror novella The Turn of the Screw (1898). Both authors use the same storytelling strategy of framing the main narrative by setting its beginning in a time much later than the events of the actual story, and then flashing back to a first person narrator telling the story in its own time-frame. Both novels also use a Victorian ghost story as a device to introduce their narratives. In this case, both novels begin with a group of people telling ghost stories on Christmas Eve, which was traditionally a time for such stories in Victorian times ${ }^{2}$. The novel also has explicit connections to other novels and stories from around the time in which it is set. The novel's title, for example, appears to be an adaptation of Wilkie Collins' The Woman in White (1859), one of the first mystery novels of the time. Through these intertextual connections, Hill situates The Woman in Black within the Gothic horror tradition and the literary context of the time in which the novel is set, giving it 'authenticity' as a Gothic horror story.

In terms of its generic structure The Woman in Black is typical of Gothic horror, which varies from the prototypical narrative structure of orientation, complication and resolution (see Eggins 2004, 250-253; 348-349). For example, The Woman in Black has an additional orientation stage set at a much later time than the main events of the novel, which provides the frame for telling the story by flashback. This strategy is also used in The Turn of the Screw, a canonical Gothic horror story. In addition, The Woman in Black has a series of complications which are unresolved, which has the effect of 
building tension and suspense as the story proceeds from one unresolved complication to the next. Tension is built until it is released by a false resolution. After each false resolution the tension rebuilds from a higher base than previously and the time between complications shortens as the pace of the tension-building accelerates.

Hill has chosen to use a first person narrator in the novel. This is an important choice as it opens up the potential for doubt from the beginning. Instead of having the story conveyed by an omniscient third person narrator, the author has chosen to have the story told by a character in the story. The reader only knows what is being done, being thought and happening from that character's point of view.

In contrast to the novel's choice of first person narration, Mallatratt's (1989) adaption for the stage is presented as "play within a play" where the narrative is both delivered and performed by two main characters: Arthur Kipps, who, as an old man, recounts his experiences to an actor whom he engaged to help him tell his story to his family, and who assumes the role of young Arthur. In the play, Old Arthur assumes the role of third-person narrator, describing the setting and events, while the actor playing Young Arthur acts out physically what is said verbally by the narrator. Although the Woman in Black appears physically on the stage, she never speaks, and in many performances is not credited (Roberts 2014).

The 1989 television film breaks with the Gothic horror convention of having the story told by flashback. Although set around the same time-period as the story in the novel and the play, the narrative in the film unfolds in real time. This choice is important because, unlike in the novel and the play, the audience is not given insight into Arthur's thoughts and feelings. Instead, the viewer is positioned as an observer and is only permitted to see what is happening on screen from the viewpoints and perspectives as determined by the film's director. 


\section{Semiotic transformations of Gothic horror genre conventions: A multimodal social semiotic approach}

In order to explore the semiotic changes involved in the transformation of a novel into stage and screen productions, the analytical approach adopted here is derived from multimodal social semiotic theory, based on Michael Halliday's systemic functional theory (SFT). In SFT, semiotic resources (e.g. language, gesture, images, sounds) are conceptualised as inter-related systems which together constitute and manifest culture (Halliday 1978; Halliday and Hasan 1985). The view of multimodal semiosis, in which recognizable configurations of semiotic choices constitute social practices, provides the basic foundations of the SFT approach. Significantly, SFT is capable of handling the multi-dimensional complexity of resemiotisation in different media, as discussed below.

Systemic functional approaches to multimodal discourse analysis (SF-MDA) (e.g. see Chapter 3 in Jewitt, Bezemer, and O'Halloran 2016; O'Halloran, Tan, and E 2015a; Tan, Smith, and O'Halloran 2015) are concerned with the "grammatics" of semiotic resources, based on the assumption that the underlying organisation of semiotic resources reflects the uses (or functions) of that resource. The theorisation of semiotic resources as systems of meaning enhances our understanding of the processes through which semiotic choices combine, and allows us to trace the shifts in meaning which take place through resemiotisation in different media.

Following Halliday's SFT, systems are organised according to the functions (called "'metafunctions") which the resources serve in society (e.g. Halliday and Matthiessen 2014), that is, ideational meaning, which consists of experiential meaning to structure experience of the world and logical meaning to make logical connections in the world; interpersonal meaning to enact social relations and create a stance towards 
the world; and textual meaning to organise experiential, logical and interpersonal meanings into messages.

The metafunctionally-based systems of meaning are represented as system networks with a series of options which describe the meaning potential of semiotic resources. For example, systems of meaning have been formulated for language (Halliday and Matthiessen, 2014; Martin and Rose 2007), static images (Kress and van Leeuwen 2006; O'Toole 2011), music (van Leeuwen 1999), action (Martinec 2004) and film resources (Bateman and Schmidt 2012). While the metafunctional principle that each semiotic resource is organised to realise different strands of meaning simultaneously (i.e. experiential, logical, interpersonal and textual) can be applied to any semiotic system, the underlying systems and networks of choices are different for each semiotic resource. That is, semiotic resources have differential capacities with regard to the metafunctions and the subsequent meanings which are made.

Multimodal texts are characterised in terms of options selected from the systems which realise the metafunctions. The novel, for instance, relies for the most part on one semiotic resource, written language, for meaning making. The analysis thus focuses on how choices from the system of transitivity (i.e. the types of processes, participants and circumstances), noun groups and phrases, and thematic choices are deployed for advancing the narrative and for creating tension and suspense. The systems are summarised in Table 1(a).

In addition to spoken language, stage performances have a greater range of semiotic resources available for meaning making and engaging audiences through elements of mise-en-scène, including stage design, the actors' positioning on the stage, movement, costume, props, lighting, sound, special effects, and so forth. Originally intended as a low budget production, Mallatratt's (1989) play is notable for its 
minimalist setting, consisting mostly of assorted boxes, chairs and trunks which are utilised in the various roles of train carriage, horse buggy, desk, bed etc. As suggested by Mallatratt (Adaptor's Note, 1989) "the only aspect of the play that has any claim to complexity is the sound plot $[\ldots]$ when just by raising the volume of a sound cue to an unexpected level, the audience can be shocked to screaming pitch". Apart from the soundtrack, the analysis of the play also focuses on the way semiotic resources are used as foregrounding devices for placing prominence on a particular character (e.g. narrator, protagonist and antagonist), setting or prop through elements of mise-en-scène such as lighting, placement on the stage, sound, and special effects. The systems are outlined in Table 1(b). Although videotaped performances also feature cinematographic resources, such as zooms and pans, these represent the particular viewpoint of the (in this case, amateur) camera operator (presumably a member of the audience), and are thus ignored in the analysis of the play. Conversely, filmic performances deploy cinematographic resources specifically for engaging the viewer and creating tension and suspense. Hence, in the analysis of the 1989 television film the use of the cinematographic systems of Camera Movement, Camera Distance, Camera Angle, Focus or Depth of Field, Point of View and the mise-en-scène system of Character Position, are investigated. The systems are displayed in Table 1(c). 
Table 1: Systems for creating tension and suspense in the novel, play and film

Semiotic Resourcel System Choice Description/Meaning Potential
System

(a) NOVEL

GRAMMATICAL SYSTEMS (LANGUAGE):

$\begin{array}{lll}\text { Process (verb) type } & \begin{array}{l}\text { Identifies the protagonists in the novel. Main protagonist is also } \\ \text { narrator. } \\ \text { What kinds of activities (mental, material action etc.) the characters } \\ \text { engage in. }\end{array} \\ \begin{array}{l}\text { Circumstances (prepositional } \\ \text { phrases, adverbs }\end{array} & \begin{array}{l}\text { Establish setting in time and place, physical environment. } \\ \text { Topical and Marked topical themes } \\ \text { (prepositional phrases and } \\ \text { adverbs as theme) }\end{array} & \begin{array}{l}\text { Function as points of departure for events in the novel. Highlight the } \\ \text { physical setting when they are in first position. }\end{array} \\ \text { DISCOURSE SYSTEMS: } & \text { Narrative } & \begin{array}{l}\text { Variations on prototypical narrative structure are exploited to build } \\ \text { tension through false resolutions, which lead on to further } \\ \text { complications. }\end{array}\end{array}$

(b) PLAY

MISE-EN-SCÈNE:

PROMINENCE/

FOREGROUNDING

Narrator

Protagonist

Antagonist

Setting/Prop

\section{SOUNDTRACK:}

TYPE OF SOUND

Voice-over narration

Sonic flashback

Human sound

Animal sound

Object sound

Natural sound

Sound effect

Music - drone

Music - tinkling

Music - orchestral

SOUND VOLUME Very loud

Loud

Normal

Soft

Very soft

(c) FILM

\section{CINEMATOGRAPHIC RESOURCES:}

\section{CAMERA MOVEMENT Stationary}

Arc up/arc down

Forward/backward

Pan right/pan left

Whip pan right/left
One hears the voice of a character/narrator, but the character in question is not speaking those words on stage.

Describes the technique of using sound from an earlier scene, which the character is hearing or imaging during a later scene.

Voices, whispers, groans, moans, cries, screams, footsteps, etc.

Barking, neighing, cawing, etc.

Creaking doors, knocks, bumps, etc.

Rain, howling wind, thunder etc.

Artificially produced sound, used for emphasis, e.g. loud percussive noises, screeches, bangs etc.

Synthesized sounds, e.g. slow drone, haunting background music.

Tinkling sound coming from a music box, etc.

Orchestral type of background music, e.g. strings, flutes etc.

A very loud sound can be frightening and lead to a 'jump scare'.

A loud sound tends to be more prominent.

A normal sound is neutral.

A soft sound tends to be less prominent.

A very soft sound often leads to the build up of the tension. 


$\begin{array}{ll} & \begin{array}{l}\text { Tracking forward/ } \\ \text { backward/alongside } \\ \text { right/alongside left }\end{array} \\ & \text { Zoom in/zoom out } \\ & \text { Tilt up/tilt down } \\ \text { Pedestal up/pedestal down } & \text { Extreme long shot } \\ \text { CAMERA DISTANCE } & \text { Long shot } \\ & \text { Medium long shot } \\ & \text { Medium shot } \\ \text { Medium close shot } \\ \text { Close shot } \\ \text { Extreme close shot } \\ \text { Eye level } \\ \text { High angle } \\ \text { CAMERA ANGLE } \quad \text { Low angle } \\ \text { Canted angle }\end{array}$

\section{FOCUS/DEPTH OF FIELD}

POINT OF VIEW

MISE-EN-SCÈNE:

\section{Deep focus}

Shallow focus

foreground/background

Soft focus

Protagonist perspective (PP)

Antagonist perspective (AP)

Dark voyeur perspective (DVP)

Viewer perspective (VP)

CHARACTER/VIEWER Frontal POSITIONING

Oblique
Profile

Over shoulder

Back to camera

Body part

Setting/Prop
Tracking shots enable the audience to feel as if they are moving alongside the actors/action on-screen. Tracking forward: the camera follows the character who moves ahead of the camera. Tracking backward: the camera moves ahead of the character who walks toward the camera.

Zooming in shows the scene or subject in more detail and brings the viewer closer. Zooming out shows the scene or subject in less detail and distances the viewer.

The camera moves at an angle upwards or downwards.

The camera moves up or down on a vertical plane with respect to the subject.

In an extreme long shot the human figure is barely visible.

A long shot gives a full view of the human figure, together with background.

In a medium long shot the human figure is framed from about the knees up.

A medium shot frames the human body from the waist up.

A medium close shot frames the body from the chest up.

A close shot shows just the head and shoulder.

An extreme close shot singles out a portion of the face, hands, feet, or a small object.

The viewer looks straight at the image and hence is (typically) positioned as an equal.

The viewer looks down on the image from a high angle and hence is (typically) placed in a position of power and superiority.

The viewer looks up at the image from a low angle and hence is (typically) placed in a position of inferiority.

Canted or oblique angles, where the camera is not level but tilted, can suggest danger or disorientation.

Foreground, middleground and background are all in focus.

Only one plane of the frame is sharp and clear, either the foreground or the background.

The focus is blurred deliberately, resulting in a dreamlike image. A fuzzy image can also suggest rapid movement.

The on-screen scene/action is presented from the viewpoint of the protagonist.

The on-screen scene/action is presented from the viewpoint of the antagonist.

Dark voyeur perspective is a framing device used to imply a character is being watched (or pursued) by a malevolent other. Includes shooting through branches, window curtains, or from within a darkened closet.

The audience is positioned as an (objective) onlooker or observer.

Characters are facing the camera directly, which works to involve the viewer.

Characters are positioned at an oblique angle, not looking at the camera, or not looking at it directly.

Characters shown in profile create the impression of either looking at something off-screen, or of being lost in their own thoughts.

Shots where the camera is positioned behind the character's shoulder, function to align the viewer with the character's point of view.

Characters positioned with the back to camera can imply that they are being watched.

Only a character's body parts (hands, feet) are shown, either from the viewer's or the character's perspective.

The viewer is positioned looking at the setting or a prop, either from the viewer's or the character's perspective. 
To handle the complexity of such analyses, the software tool Multimodal Analysis Video ${ }^{1}$, which is specifically designed to explore semiotic interactions in dynamic media (e.g. O’Halloran, Tan, and E 2015a, 2105b; Tan, Smith, and O'Halloran 2015), was used for the analysis of the (video-recorded) theatrical performance and the film, discussed in the following section.

\section{Analysis}

In order to demonstrate how each performance medium has its own unique set of semiotic resources for meaning making which are accessed in the novel, a videotaped performance of the play, and the 1989 television film respectively, the analysis focuses on two key episodes which are pivotal in the narrative.

\section{Episode 1: Arthur encounters the Woman in Black}

The first episode analysed describes Arthur's second encounter with the Woman in Black. It is here that Arthur begins to believe that he is dealing with the supernatural. Arthur is shaken by this encounter and questions whether the Woman in Black is a real person or whether she is a ghost.

\section{1a. The 1983 novel}

Arthur's response to his sighting of the woman in the abandoned graveyard on the grounds of Eel Marsh House plays a key role in the building of tension in the novel. In his previous encounter with the Woman in Black at Mrs Drablow's funeral, he was quite sympathetic towards her: "I had not noticed any particular expression on her ravaged face, but then I had, after all, been entirely taken with the look of extreme illness" (Hill 1983, 74). After seeing her in the abandoned graveyard, his view of her has changed. Her expression now had "a desperate, yearning malevolence", and "she 
directed the purest evil and hatred and loathing, with all the force that was available to her" (75). From this point on, The Woman in Black is always depicted negatively.

The Woman in Black herself does not do very much in this episode. She appears mysteriously and then disappears. In this regard, she is a presence rather than an actor, and all references to her are from Arthur's point of view. However, her appearance and Arthur's response to it signals the most tense part of the episode and her departure precipitates the release of tension.

In the novel, the scene for tension-building and release is set by and foreshadowed by the physical environment, especially the weather. Prior to Arthur's encounter with the Woman in Black, the weather was "all [...] bright and clear, and there was a thin sun overall" (66). As the complication approaches, the weather changes for the worse. The physical environment and the weather are realised linguistically as circumstances, attributes in relational processes, and pre-modifiers and the main noun in noun groups and phrases. The physical setting is made prominent by through the textual organisation of the sentence; for example, circumstances are placed as marked themes at the beginning of key paragraphs: "In the greyness of the fading light" (74); and "But, out on the marshes, just now, in the peculiar fading light and desolation of that burial ground..." (78). The physical environment features as a background setting for the whole episode, as references to the environment, realised in noun groups, e.g. "the extreme bleakness and eeriness of the spot" (74); "a decayed and abandoned air" (73), occur throughout the episode rather than at specific points.

The transitivity of the episode (in terms of processes, participants and circumstances) also contributes to building tension. In the sections before tension is created and after it is released Arthur primarily engages in fairly routine material, behavioural and mental processes: he walks, stands, sees, emerges, watches and likes 
(72-74). As tension is built Arthur's participant roles change and, linguistically, he is more often the senser in mental processes of perception and cognition. In processes of perception, the phenomenon that is observed is usually the Woman in Black (or some part of her): "I had seen a woman whose form was quite substantial and yet in some essential respect also, I had no doubt, ghostly" (78-79).

The tension that is built steadily is crystallised when the physical environment, the Woman in Black and Arthur are participants in the same clause, for example, when Arthur reflects on his encounter: "For the combination of the peculiar, isolated place and the sudden appearance of the woman and the dreadfulness of her expression began to fill me with fear" (75). Here the woman and the environment both act together on Arthur to terrify him.

\section{1b. The play (2011 performance)}

In the play, Arthur's second encounter with the Woman in Black occurs as he takes a stroll through the abandoned burial ground after his arrival at Eel Marsh House. In the play, the atmosphere is created in part by Old Arthur's narrative, and the willing suspension of disbelief on part of the spectator. Instead of describing the scene in terms of relational processes (e.g. "the stage $\underline{i s}$ a island"), by drawing on mental processes ("imagine") the narrator demands of the audience that they construe their own experience of the world (see excerpt of transcript of spoken narrative in Figure 1a). 


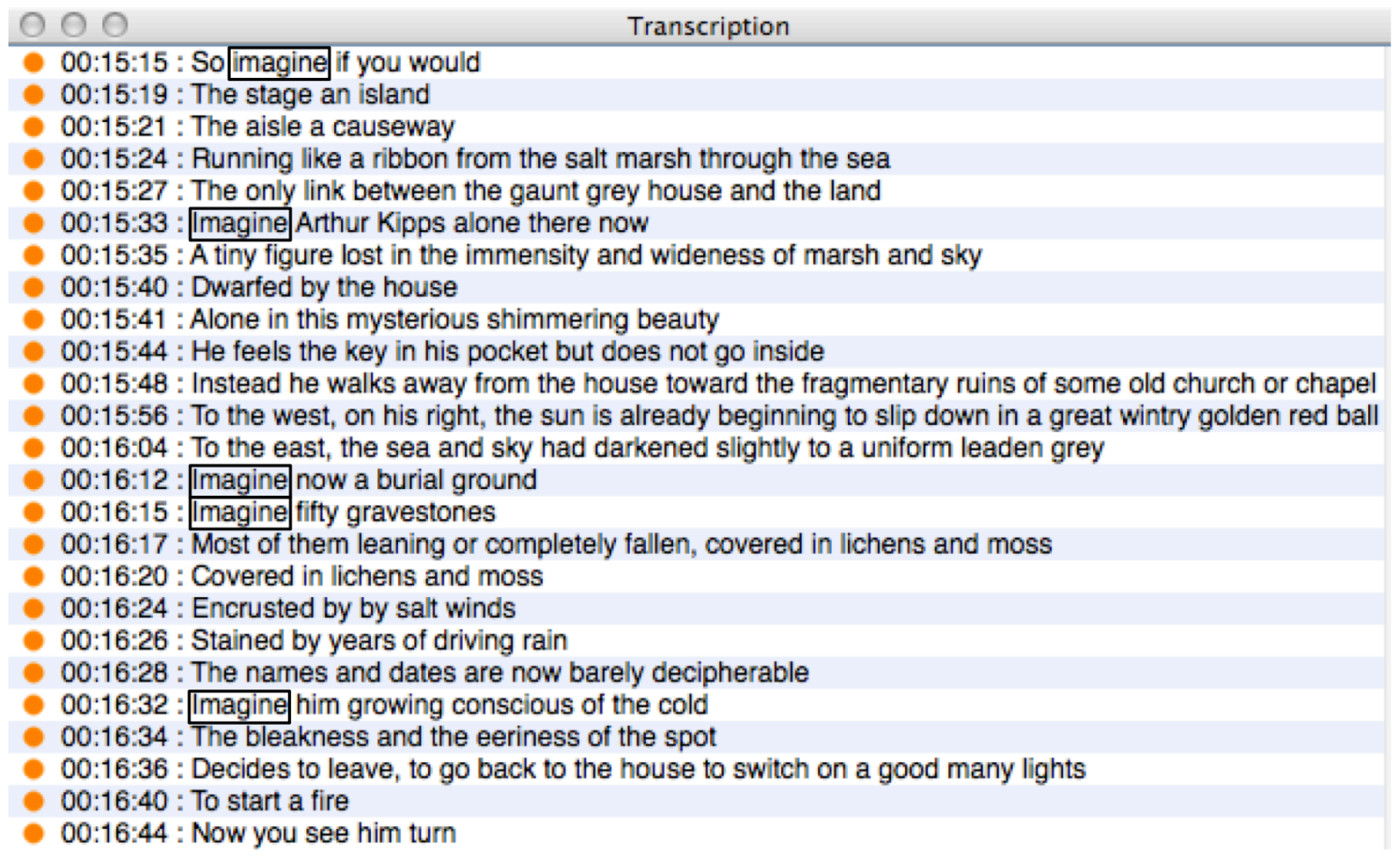

Figure 1a. Excerpt of transcript of spoken narrative, Old Arthur as narrator (2011 performance)

Apart from using spoken language, the play also uses audio and visual cues to provoke the audience's imagination, and to create terror and fright. In order to investigate how these multiple semiotic resources are co-deployed for the purpose of creating tension and suspense in a theatrical performance, the analysis of the videotaped play was carried out with the aid of the purpose-built software tool Multimodal Analysis Video $^{3}$ which provides facilities for viewing the video in a player window [1] and film strip [2], inserting time-stamped annotation nodes [3] in system strips [4], and selecting a system choice [5] from the list of available system choices [6]. All annotations are synchronised with the video player, the film strip, the sound strip [7], the time-stamped nodes in the dialog strip [8], and the corresponding verbal transcriptions in the transcription window (shown in Figure 1a.) Figure 1b provides a snapshot of the scene described below, as analysed in Multimodal Analysis Video. The analysis illustrated in Figure $1 \mathrm{~b}$ shows, for example, how tension is created in a break in the narrative by the 
haunting background music, which steadily rises in volume, while the audience's gaze is directed to the centre of the darkened stage where a beam of diffused lighting tentatively picks out the shadowy form of a veiled woman lurking amidst the imaginary graves. Like Arthur, the audience is left in doubt who or what she is. As in the novel, the Woman in Black is resemiotised as a ghostly presence that is sensed, imagined, rather than seen. As Mallatratt (Adaptor's Note, 1989) expounds, "Darkness is a powerful ally of terror, something glimpsed in a corner is far more frightening than if it's fully observed". Moreover, the uncertainty surrounding the Woman in Black's materiality serves to accentuate Arthur's confusion and doubt, who reiterates at the end of the scene that he "did not believe in ghosts".

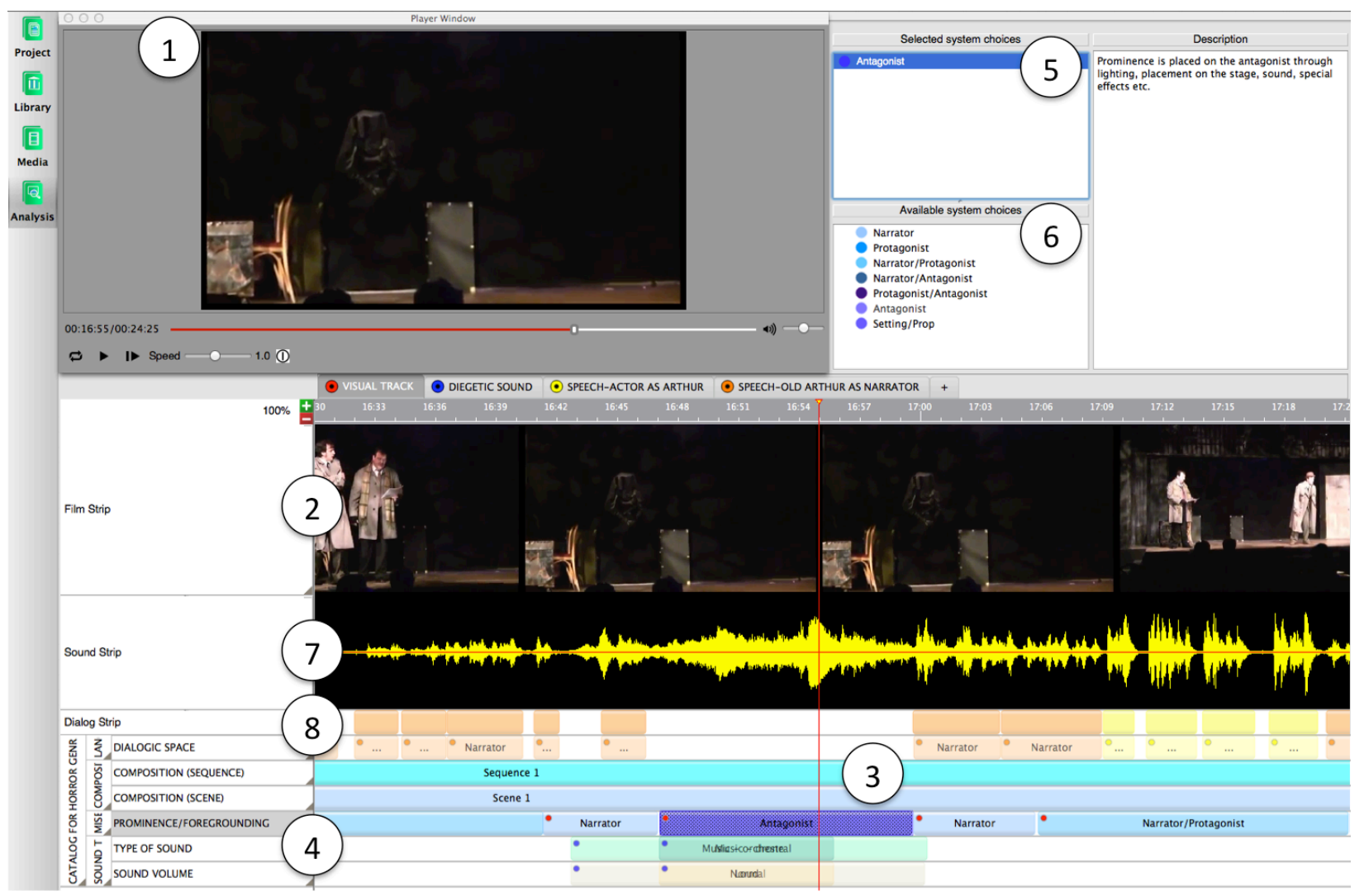

Figure 1b. Arthur glimpses the Woman in Black in the abandoned burial ground (2011 performance) (Notation: Player window [1], film strip [24], time-stamped annotation nodes [3], system strips [4], selected system choice [5], list of available system choices [6], sound strip [7], dialog strip [8]) 


\section{1c. The 1989 television film}

In the film, the atmosphere during his encounter with the Woman in Black is very different, as Arthur takes a stroll through the abandoned burial ground in broad daylight. As he is about to return to the house, he suddenly stops in his tracks, turns, and sees the Woman in Black at a distance. Startled by her sudden appearance, Arthur stumbles, with the camera stumbling with him in alternate tracking and stationary shots as he starts and stops and turns about. The Woman in Black, in contrast, just stands there, staring malevolently at Arthur. Filmed from a $180^{\circ}$ perspective, each shot-reverse-shot brings them closer in terms of camera distance (see film strip [1], Figure 1c). As the camera zooms in on the menacing countenance of the Woman in Black in a close shot as she takes a step forward (see film strip [2], Figure 1c), Arthur panics and runs back to the house, trailed by the camera. The scene is accompanied by a haunting background melody, which builds tension by steadily rising in volume (see sound strip [3], Figure 1c) as Arthur and the Woman in Black stare at each other. The background music stops abruptly, releasing the tension, as Arthur reaches the house and slams the door.

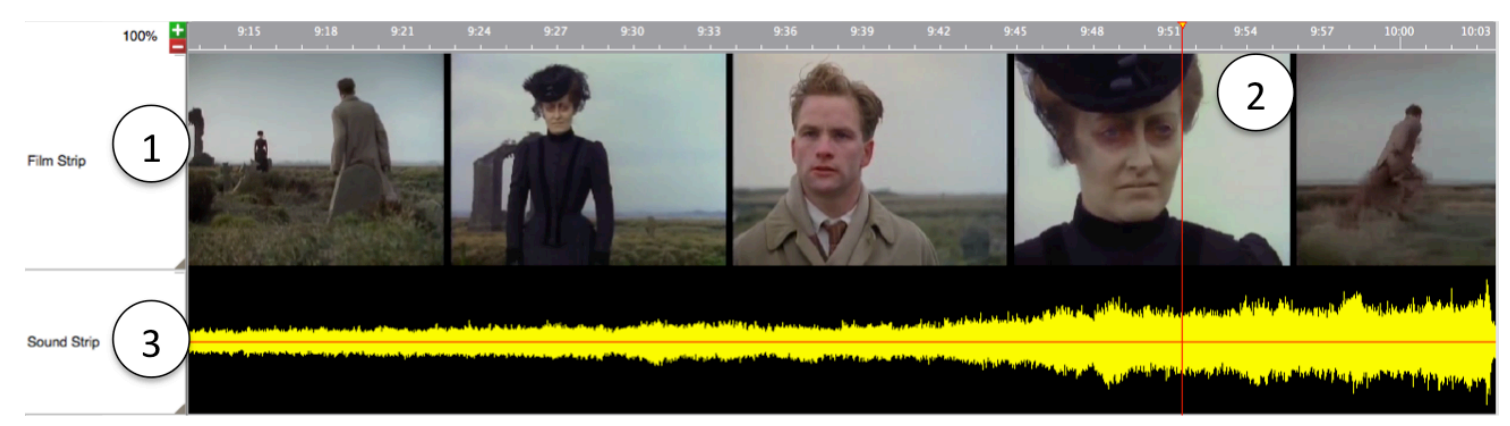

Figure 1c. Arthur encounters the Woman in Black in the abandoned burial ground (1989 TV film) (Notation: unfolding action filmed from a $180^{\circ}$ perspective [1]; close shot of Woman in Black [2]; sound waves representing haunting melody [3])

\section{Episode 2: In the nursery}

The second episode analysed below describes the scenes revolving around the nursery, 
which constitute the scare-climax in the novel, the play, and the film. The episode takes place after Arthur found out the true identity of the Woman in Black and her sinister intentions.

\section{2a. The 1983 novel}

In the novel, an entire chapter is devoted to the events in the nursery, which occur after Arthur has returned to Eel Marsh House to complete his work, this time accompanied by the dog Spider, as suggested by Samuel Daily, a wealthily local landowner who befriended Arthur. The chapter contains six tension-building episodes, each of which increases the tension and then partially releases it before building tension again from a higher base. The partial release of tension is briefer each time, until a peak is reached in the penultimate episode.

As before, the atmosphere is first established through the weather which is placed thematically at the beginning of the sentence: “The fine clear weather still held, there was sunshine and blue sky again, when I drew the curtains"; "my mood was unchanged, I was determined and optimistic" (123). On his return to Eel Marsh House Arthur sets about the routine of his work, sorting through Mrs Drablow's papers and settling himself in at the house. The weather remains fine: "I looked out of the wide windows at the marshes, unshadowed still and quietly beautiful in the winter sunlight" (126). Arthur decides to take a break and go for a walk outside with Spider. He ventures into the old cemetery where he had seen the Woman in Black, but this time nothing sinister happens: "No harm had befallen me"(129). After work and reading for a while Arthur goes to bed and falls asleep. In the written equivalent of a 'jump scare', he is woken up suddenly by the sound of the dog growling. He hears a muffled noise. Arthur then engages in a number of mental and behavioural processes: he "heard", "could not make out" and was "listening" (131). The tension starts to build as he explores the 
house looking for the source of the sound. Here the descriptions become more ominous: "silence, a seething, blanketing, almost tangible silence, and a musty darkness, thick as felt" (132). He locates "the sound of something bumping gently on the floor, in a rhythmic sort of way": "Bump, bump. Pause. Bump, bump. Pause. Bump, bump. Bump, bump. Bump, bump" (132) as coming from behind a locked door. Arthur's emotional state is now one of "bewilderment and terror" (134) until he hears another soft sound coming from behind him. Arthur investigates the locked door again and then goes back to bed.

The previous episode ends with tension still high and unreleased. The next episode begins with the tension still high. This is signalled by a change in the weather: "I felt that the air had a dampness in it and it was rather colder and, when I looked out of the window, I could hardly see the division between land and water, water and sky, all was uniform grey, with thick cloud lying low over the marsh and a drizzle" (135).

Later, Arthur returns to Crythin Gifford for supplies and then returns to Eel Marsh House. He and the dog are then startled again by a noise, which turns out to be the bumping sound coming from behind the locked door. Arthur decides that he must investigate and runs off to find an axe to chop open the door. He goes outside to get the axe. The physical environment again plays a role: "it was pitch dark: there was neither moonlight nor any stars visible" (140). In the darkness Arthur hears the sound of the pony and trap again and "then with an awful cry of realization, I knew. There was no visitor - or at least no real, human visitor ..." (141). Arthur then "stood hideously afraid" (141); and "could do nothing but stand, stand as still and stiff as a post, rigid with fear and yet inwardly in a turmoil of nervous apprehension and imaginings and responses" (142). The dog also responds: it "began to howl, a loud, prolonged, agonized 
and heart-stopping howl" (142). Having the dog respond with similar emotions to Arthur places the dog in the role of corroborating witness, authenticating the story.

There is no period of calm between this episode and the next episode. Still distressed, Arthur returns to the house and the locked room, only to find that the door is now open. This puts him into a state where "I do not know how long I stood there in fear and trembling and in absolute bewilderment. I lost all sense of time and ordinary reality" (145).

A similar pattern of development to that found in the previous episode is found in this chapter, with some key differences. In the previous episode discussed there is a pattern where Arthur is confronted by the weird and seemingly inexplicable. He becomes disoriented and disordered. He then regains his composure by reflecting on what has happened. Following this, tension is, at least partially, released and a state of some order is restored. In this chapter, during the most tense events, Arthur does less reflecting. His reactions are more intense and physical, realised through behavioural and material processes. He was "breathing fast", "my heart seemed to be leaping about madly", "my fear reached a new height", "I thought I would die of it" (145). Following his realisation that the sound is coming from a rocking chair the tension eases: "I was soothed and sleepy again", "I was breathing slowly and more deeply”, "felt a warmth creeping into my limbs" (146). He calms down and reflects (and reminisces) again.

\section{2b. The play (2011 performance)}

Like in the novel, the scenes revolving around the nursery form the high point in the creation and release of tension, which rises and falls in waves, until reaching a climax with the Woman in Black damaging and destroying objects in the nursery.

The scene analysed below takes place after Arthur has returned to Eel Marsh House with Spider (which in the Main Street Players' stage performance can be heard 
but not seen). After going through Mrs Drablow's documents, Arthur falls asleep. At this instant, a vague noise can be heard from coming behind the locked nursery door. Awakened by Spider's bark, Arthur gets up and follows the (imaginary) dog to investigate where the sound is coming from. In this scene, sound and lighting play key roles in creating suspense. According to Bordwell and Thompson (2010: 136) blue lighting can suggest terror and uncertainty, while the soundtrack can cue the audience to form certain expectations, which may or may not be fulfilled. For example, as Arthur follows the imaginary dog around the dimly illuminated stage, a very loud and sudden sound effect mimicking the flapping noise of a bird flying in through a window or fireplace while Arthur is seen waving his hands over his head fending off the imaginary bird (see film strip [1], and tightly grouped sound waves [2] on the left in Figure 2a) creates a "faux jump scare" . The tension is relieved only momentarily, however, and continues to build up again as Arthur approaches the locked nursery door. This time, a feeling of foreboding is created by the sound effect, which - now overlaid with haunting voices and the sound of a baby's cry - slowly begins to intensify in volume (see jagged sound waves [3] in the sound strip on the right in Figure 2a). The tension is finally broken by the calm voice of the narrator describing the serene scene that Arthur perceives looking out of the (imaginary) window: "There lie the marshes, sliver-grey and empty. There is the water of the estuary. Flat as a mirror with the full moon lying upturned upon it", and by Arthur himself, who reassuringly dismisses the eerie noises as "Just the wind and nothing more". 


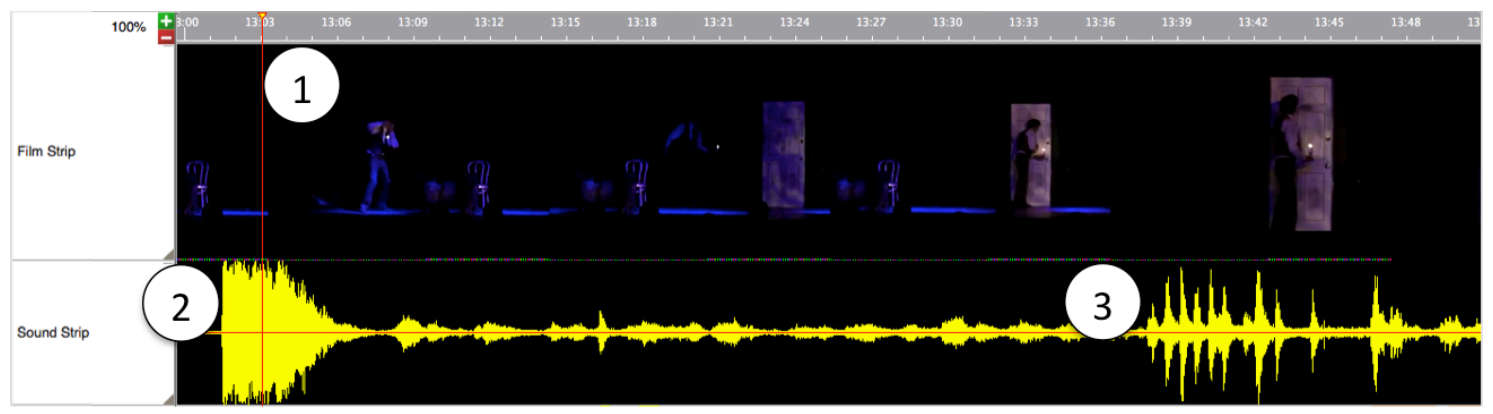

Figure 2a. Faux jump scare, and eerie noises (2011 performance) (Notation: Arthur fending off imaginary birds [1]; "faux jump scare" represented by tightly grouped sound waves [2]; jagged sound waves representing eerie noises [3])

Once again, the tension is released only briefly and continues to mount again in the following scene, which starts with Spider being startled by strange sounds coming from behind the locked door. In this case, lighting is used as a foregrounding technique to give prominence to the nursery door, which is now mysteriously open. In this scene, the prop becomes the main focus of attention (leaving the audience in suspense of what might lurking behind), while the rest of the stage is in darkness (see film strip [1] in Figure 2b).

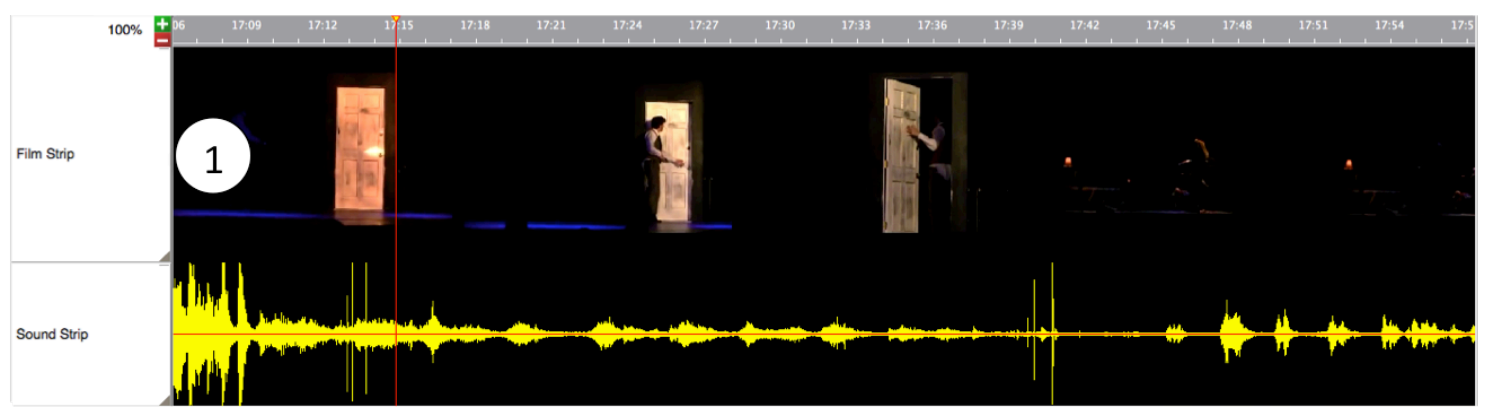

Figure 2b. The nursery door (2011 performance) (Notation: Prominence placed on nursery door through lighting [1])

The scene that takes place inside the nursery is, by contrast, not at all scary or suspenseful. The audience watches Arthur calmly explore the nursery and pick up toys, complemented by the descriptive narrative provided by the offstage narrator. The softly 
tinkling sound of child's music box that accompanies the scene only serves to accentuate Arthur's own voiced sentiments: "There is nothing here to frighten me [except for] a feeling of something missing”. Tension only picks up again when Arthur suddenly drops his torch, created in part by the frantic pace and pitch of Arthur's exclamations (“THE TORCH. Where is the torch? The torch. Where is it?"), and emphasised by illumination, or the lack of it, as the stage is cast alternatingly in complete darkness and ambient red lighting as Arthur gropes for his torch in the dark.

Sound effects, however, need not necessarily be loud and sudden to create a chilling atmosphere. In the following scene, in which Arthur runs offstage in search of Spider who has vanished after hearing a whistling sound, the softly tinkling music box sound, which in the earlier scene only contributed to create an innocent atmosphere, now assumes a more sinister meaning. As the tinkling melody slowly increases in pace and volume, the audience's attention is focused on the shadowy figure of a woman which can be vaguely glimpsed (rather than clearly seen) moving around the darkened stage manipulating objects (ostensibly destroying the nursery). Here, the ambient lowkey lighting creates an almost unbearable tension, which is suddenly released, accompanied by a sharp snapping sound, before transitioning to the next scene.

\section{2c. The 1989 Television film}

In the film, the episode analysed below takes place after Arthur, hearing the sound of a pony and trap crashing into the marsh, returns to the house to record his experience into a phonograph. He then rises to stoke the fire. At this moment, Spider the dog wakes up and barks, reacting to the hushed sound of a bumping noise (see jagged sound waves in sound strip [1], Figure 2c). Arthur follows the dog upstairs, along the corridor and stops in front of the locked nursery door, from behind which the bumping noise seems to be emanating. Arthur edges closer and tries to open the door, but it will not budge. A 
frenzy of activity then ensues, augmented by the soft and fuzzy camera focus, as Arthur runs back downstairs to look for an axe to break open the lock, and runs back upstairs towards the nursery door, which is now open. Tension reaches a high point as Arthur stands still and stares at the open door, filmed from the protagonist's perspective (see film strip [2], Figure 2c). The tension continues to build as he advances slowly towards toward it, axe in hand, accompanied by slow, haunting background music (see sound strip [3], Figure 2c).

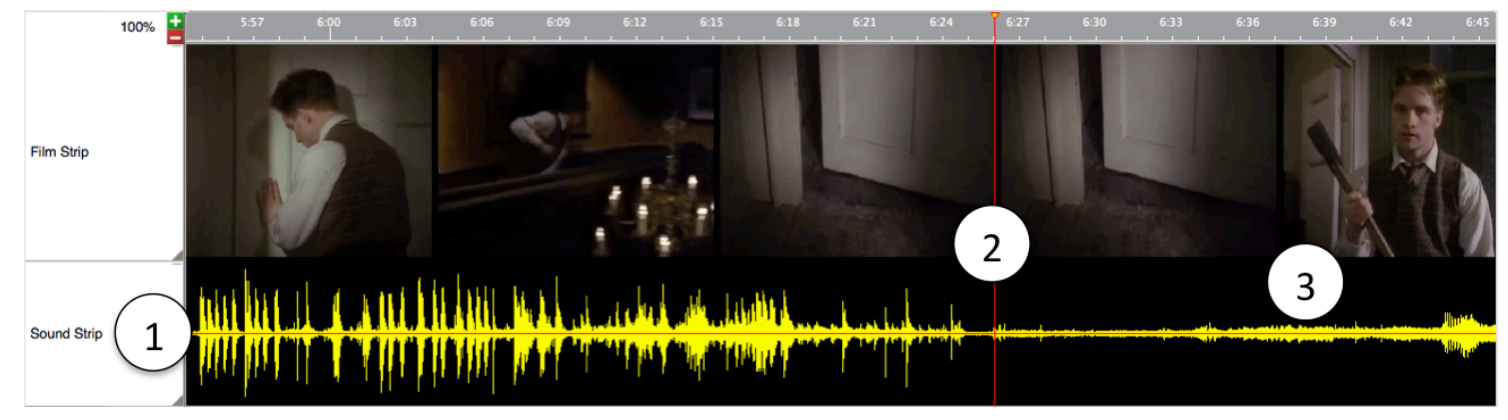

Figure 2c. The nursery door (1989 television film) (Notation: Sound waves representing bumping noises [1]; the nursery door viewed from the protagonist's perspective [2]; sound waves representing slow, haunting background music [3])

In the film, the scene inside the nursery deviates slightly from the events described in the novel and is resemiotised as follows. The bumping noise, it appears, was coming from a bouncing leather ball (not a rocking chair). The viewer watches Arthur pick up the ball and examine it with a puzzled look. The viewer is then led to follow Arthur's gaze as he scans the nursery from the protagonist's perspective. Accompanied by the sound of softly tinkling background music, the camera then reveals the objects that are described through written language in the novel and Old Arthur's narration in the play: a small child's bed, toy figurines on the mantelpiece, harlequin puppet, black Sambo doll, toy house and toy soldiers. Until then, the scene in the nursery seemed benign, allowing for a release in tension. However, the tension sets in 
again suddenly as the softly tinkling music box sound is replaced by loud jarring violin strings. Then the background music stops abruptly, only to be punctuated by the sound of a child's voice saying "hello", followed by playful laughter. The invisible child says "hello" one more time and then places a small toy soldier into Arthur's hand. The viewer is closely involved in this scene, as in an extreme close shot the camera lingers on the tiny toy soldier in Arthur's hand (see film strip [1], Figure 2d). The child's soft laughter is heard again and then the light suddenly goes out. The tension reaches a climax as Arthur runs from the room in a frenzied state of agitation, once again amplified by fuzzy camera focus, and accompanied by fast and loud slashing string music which is strongly reminiscent of the soundtrack in Alfred Hitchcock's infamous shower scene in the (1960) horror film Psycho (see jagged sound waves in the sound strip [2], Figure 2d).

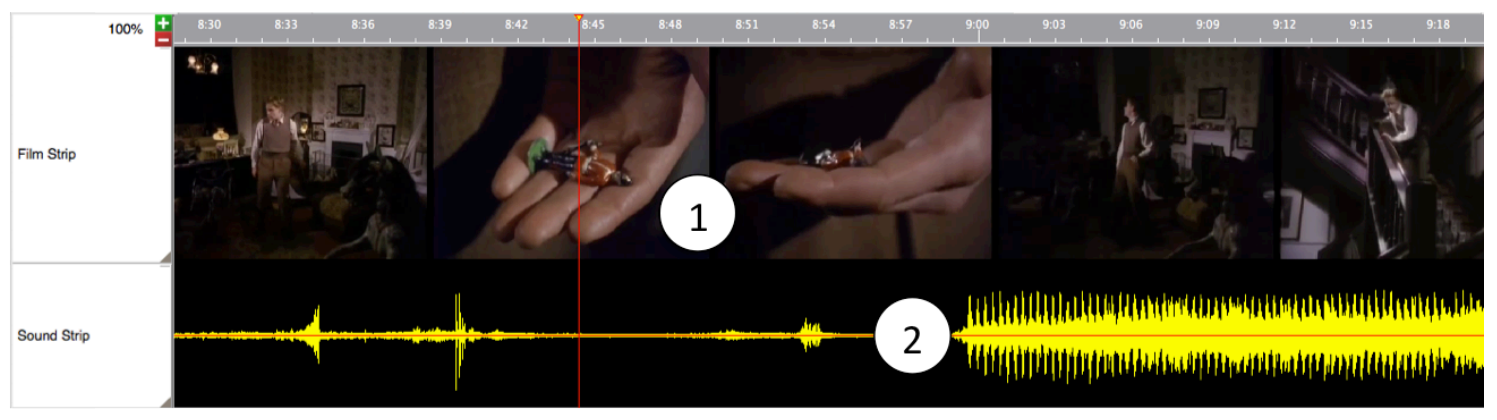

Figure 2d. Arthur receives a toy soldier from a ghost child (1989 television film) (Notation: Extreme close shot of toy soldier in Arthur's hand [1]; sound waves representing loud slashing string music [2])

In contrast to the play, the scene where Arthur returns to the destroyed nursery is de-emphasised in the 1989 television film. In a very short scene, the camera focuses on Arthur in a medium close shot as he slowly opens the nursery door. The next shot reveals that the nursery is now in disarray. The scene is accompanied at first by slow, haunting background music, which swells to the same loud jarring strings heard earlier 
in previous scene. After seeing the destroyed nursery, Arthur collapses and is helped out of the room by Samuel Daily (referred to as Toovey in the 1989 film).

While the Woman in Black kept her distance in the scenes just analysed, she makes another appearance in the following scene, which constitutes the scare climax in the 1989 television film. After his dizzy spell in the nursery, Arthur spends the night at Sam Daily's house. Preparing for bed, Arthur goes through the contents of a trunk taken from Eel Marsh House. Accompanied by tinkling background music reminiscent of the sound from a child's music box, the camera focuses on Arthur's hand in an extreme close shot from the protagonist's perspective, as he finds the tiny toy soldier given to him by the ghost child. The viewer then watches in a very long sustained shot as Arthur goes to bed and falls asleep. A very long dissolve, lasting about two seconds, leads to the impression that the following scene may be interpreted as a dream sequence. Indeed, in the next shot, the camera zooms in on Arthur as he turns and tosses in his sleep, accompanied by a haunting, drone-like sound, which increases in volume as Arthur wakes up, bathed in sweat, holding the toy soldier in his hand. The viewer then watches Arthur through the bedposts from a dark voyeur perspective (see film strip [1], Figure 2e), as a child's voice suddenly says "hello" and "it's for you". In answer to Arthur's queries “where are you?", "who are you?", the unseen child only giggles. Suddenly, in the next shot, in a jump scare, the Woman in Black's menacing countenance with budging eyes and bared teeth can be seen hovering over Arthur from the protagonist's perspective (see film strip [2], Figure 2e). The camera continues to zoom-in on the Woman in Black's face from the protagonist's perspective, with each shot bringing her closer to Arthur (and by implication, the viewer), until her face is shown in an extreme close-up (see film strip [3], Figure 2e), accompanied by a very loud sustained shrieking sound, which mixes with Arthur's own screams (see sound strip [4], Figure 2e). The 
shot ends with a very long fade-to-black, again lasting about two seconds. Although this could be due to the prevailing cinematographic conventions at the time the film was produced, it nevertheless works to enhance the dream-like feeling. The next shot shows Arthur lying in bed in broad daylight with a fever, reinforcing the impression that the apparition of the Woman in Black may have been only the product of Arthur's feverish dreams.

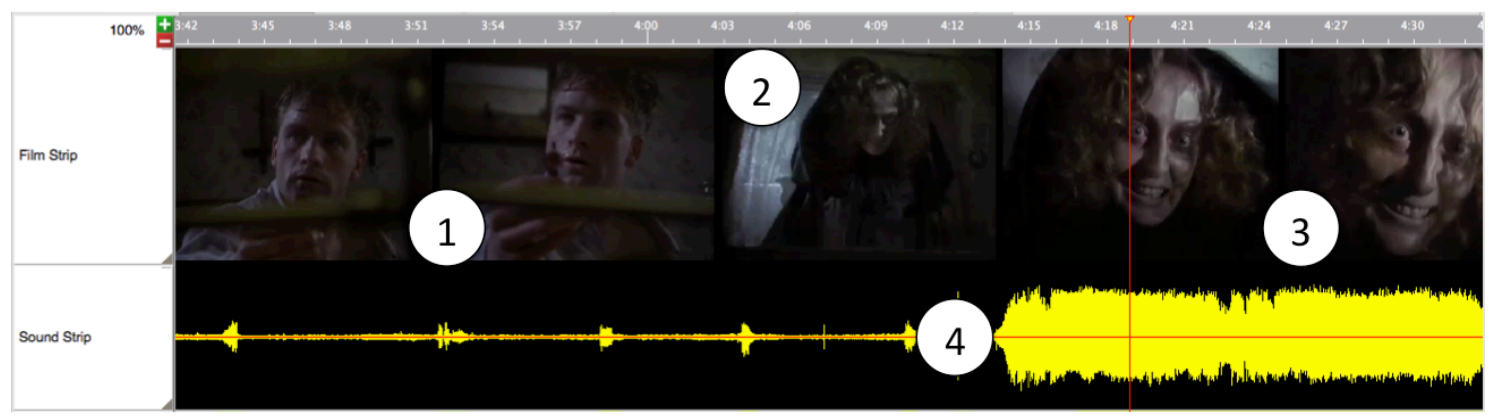

Figure 2e. The Woman in Black appears in Arthur's feverish dreams (1989 television film) (Notation: View of Arthur from a dark voyeur perspective [1]; the Woman in Black from the protagonist's perspective [2]; extreme close shot of Woman in Black [3]; sound waves representing loud shrieking sound and Arthur's screams [4])

\section{Discussion}

The above analysis illustrates how a multimodal social semiotic approach can be applied for examining the resemiotisations that occur in the transformation of a novel into stage and screen productions. The approach was demonstrated through examples from the genre of Gothic horror in different media to explore how combinations of semiotic resources are exploited for creating tension and involving the audience in the story of The Woman in Black in the novel, the play, and the film.

The analysis has highlighted how the novel creates its overall and its local effects from choices from systems in language, register, genre, and from being situated 
intertextually in the broader cultural context of Gothic horror and nineteenth century literature.

The analysis of the play and the film performed in an interactive software environment has further illustrated how the play and the film draw on conventional Gothic horror motifs, albeit utilizing different combinations of choices from different semiotic systems. That is, semantic expansions take place as the performance draws upon theatre conventions and the film draws from film genres, and the various semiotic resources which are available in each medium. The analysis shows, for example, how combinations of choices from elements of mise-en-scène, such as low-key lighting, background music and sound effects, work together with spoken language to create tension and suspense in the play, whilst the film exploits combinations of choices from cinematographic systems and the soundtrack for achieving the same or similar effects.

In the broader cultural context, the story of The Woman in Black adopts many of the iconic features of Gothic horror. It works the way many, if not most, Gothic horror stories work, by creating uncertainty within certainty. For a reader/viewer with even a rudimentary knowledge of Gothic horror, the accumulation of classic elements of Gothic style literature and film, together with intertextual clues, tell the reader/viewer that this is a Gothic horror story. As such, an audience with any experience at all of this genre knows that this is going to be a scary story and that frightening things are going to happen. What the audience does not know, however, is what is going to happen or when it is going to happen. It is, in part this uncertainty within certainty that creates the accumulation of tension that produces the frightening effects. The reader/viewer also knows that once one complication has passed another one is coming soon.

In the novel and the play, tension is built progressively throughout the story. This happens by having the tension only partially released so that each new potential 
encounter with the supernatural starts from a higher base of tension than the previous one. Parallel with this, the periods of calm between tension-building episodes become progressively shorter as the story builds up to the ghostly encounters with the Woman in Black. The analysis has shown how the Woman in Black is resemiotised as an elusive figure, an apparition that is momentarily glimpsed, rather than clearly seen, which contributes significantly to the mystery and building of suspense in both the novel and the play. At the same time, the uncertainty surrounding the Woman in Black's materiality serves to cast doubt on Arthur's soundness of mind. Although the Woman in Black is given a more material form and substance in the film, she does not do very much apart from terrifying Arthur. As a matter of fact, there are not many frightening scenes in the 1989 television film, and only one real jump scare. The tension is created in part by the unfolding narrative, and the alternatingly haunting and jarring background music, although the effect here is perhaps less to scare the viewer, but rather to provide an insight into Arthur's increasingly perturbed state of mind as the story unfolds.

\section{Conclusion}

The multimodal semiotic approach has allowed us to investigate the mechanisms through which semiotic choices combine and to trace the transformations in meaning which take place through resemiotisations of the same Gothic horror story in different media. With the recontextualisation across different media, the techniques for advancing the story and engaging the reader/viewer change according to the platform. For example, the use of written language and first-person narrative technique in the novel for creating a haunting atmosphere and developing the characters require a certain investment by the reader. Moreover, readers will form the own individual interpretations based on their prior experience with the genre. 
In theatrical performances, a wider range of semiotic resources becomes available, enabling the setting and the characterization of the different participants to be more fully developed. Also, plays are experienced collectively, and theatre audiences are cued to form particular interpretations, for example, through the manipulation of lighting, sound, props, and the characters' movement, tone of voice, and kinetic expressions.

Each resemiotisation of the story in different media opens up access to a new, expanded meaning potential, as demonstrated by the film, which additionally draws on a wide array of cinematographic techniques for engaging the viewer and creating tension and suspense. However, the more comprehensive semiotic construction of the story (for example, the 2012 film incorporates further intertextual clues and opportunities for visceral jump scares), does not necessarily open up more room for interpretation. Quite possibly the opposite happens, where the story is presented to the viewer as a fully assembled semiotic package, leaving little to be imagined in terms of the various aspects of the story (e.g. atmosphere, setting, point of view, characterisation etc.).

From this perspective, as semiotic constructions become more sophisticated through technological advances, as does the audience's expectation of what is to be presented, semiotic choices may function to guide particular interpretations which before may have been left more open. In this respect, further investigation is required in order to assess the nature and impact of the evolving semiotic possibilities which have become available through digital technology (for example) and the actual multimodal semiotic choices which are made. The implications extend well beyond performance studies, because the multimodal recontextualisation of social practices and genres forms the underlying basis of human socio-cultural life. For this reason, the modelling and 
understanding of multimodal semiosis is a major challenge, which remains largely unresolved, at this stage at least.

Websites

1 http://www.theguardian.com/stage/theatreblog/2009/jun/11/woman-in-blackmousetrap

2 http://www.theguardian.com/books/2013/dec/23/ghost-stories-victoriansspookily-good

3 http://multimodal-analysis.com/products/multimodal-analysis-video/

4 http://filmmakermagazine.com/76622-so-you-want-to-make-a-horror-film-onjump-scares-and-other-basics-of-fright/\#.VihHW2QrLxo

References

Bateman, J. A., and K.-H. Schmidt. 2012. Multimodal Film Analysis: How Films Mean. Routledge Studies in Multimodality. London: Routledge.

Bordwell, D. 2013. "Murder Culture: Adventures in 1940s Suspense.” Accessed 30 October 2015. http://www.davidbordwell.net/essays/murder.php

Bordwell, D., and K.Thompson. 2010. Film Art: An Introduction. $9^{\text {th }}$ ed. New York: McGraw-Hill.

Brophy, P. 1986. "Horrality— The Textuality of Contemporary Horror Films.” Screen 27 (1): 2-13. doi:10.1093/screen/27.1.2.

Carroll, N. 1990. The Philosophy of Horror or Paradoxes of the Heart. New York: Routledge.

Cuddon, J. A. 2013. A Dictionary of Literary Terms and Literary Theory. $5^{\text {th }}$ ed. Chichester: Wiley-Blackwell. 
Eggins, S. 2004. An Introduction to Systemic Functional Linguistics. $2^{\text {nd }}$ ed. London and New York: Routledge.

Halliday, M. A. K. 1978. Language as Social Semiotic. London: Edward Arnold.

Halliday, M. A. K., and R. Hasan 1985. Language, Context and Text: Aspects of Language in a Social-Semiotic Perspective. Waurn Ponds, Victoria: Deakin University.

Halliday, M. A. K., and C. M. I. M. Matthiessen. 2014. Halliday's Introduction to Functional Grammar. London and New York: Routledge.

Hantke, S., ed. 2004. Horror Film: Creating and Marketing Fear. University Press of Mississippi.

Hill, S. 1983. The Woman in Black. London: Vintage Books.

Iedema, R. 2003. "Multimodality, Resemiotisation: Extending the Analysis of

Discourse as Multi-Semiotic Practice." Visual Communication 2: 29-57. doi:10.1177/1470357203002001751.

Jewitt, C. 2009. “An Introduction to Multimodality.” In The Routledge Handbook of Multimodal Analysis, edited by Carey Jewitt, 14-27. London and New York: Routledge.

Jewitt, C., ed. 2014. The Routledge Handbook of Multimodal Analysis. $2^{\text {nd }}$ ed. London: Routledge.

Jewitt, C., J. Bezemer, and K. L. O’Halloran. 2016. Introducing Multimodality. London: Routledge.

Keisner, J. 2008. "Do You Want to Watch? A Study of the Visual Rhetoric of the Postmodern Horror Film.” Women's Studies: An Inter-Disciplinary Journal 37 (4): 411-427. doi:10.1080/00497870802050019. 
Kress, G., and T. van Leeuwen. 2001. Multimodal Discourse: The Modes and Media of Contemporary Communication Discourse. London: Arnold.

Kress, G., and T. van Leeuwen. 2006. Reading Images: the Grammar of Visual Design. $2^{\text {nd }}$ ed. London: Routledge.

Mallatratt, S. 1989. The Woman in Black: A Ghost Play. London: French.

Martin, J. R., and D. Rose. 2007. Working with Discourse: Meaning beyond the Clause. $2^{\text {nd }}$ ed. London, Continuum.

Martinec, R. 2004. "Gestures that co-concur with Speech as a Systematic Resource: The Realization of Experiential Meanings in Indexes.” Social Semiotics 14 (2): $193-$ 213.

O’Halloran, K. L., S. Tan, and M. K. L. E. 2015a. "Multimodal Semiosis and Semiotics.” In The Bloomsbury Companion to M.A.K. Halliday, edited by Jonathan Webster, 386-411. London: Bloomsbury.

O’Halloran, K. L., S. Tan, and M. K. L. E. 2015b. “Multimodal Analysis for Critical Thinking." Learning, Media and Technology. doi:10.1080/17439884.2016.1101003.

O’Halloran, K. L., S. Tan, and P. Wignell. 2016 in press. "SFL and Multimodal Discourse Analysis". In The Cambridge Handbook of Systemic Functional Linguistics, edited by Jeff Thompson, Wendy Bowcher, Lise Fontaine, and Jennifer Yameng Liang. Cambridge UK: Cambridge University Press.

O’Toole, M. 2011. The Language of Displayed Art. $2^{\text {nd }}$ ed. London/New York: Routledge.

Prohászková, V. (2012). “The Genre of Horror.” American International Journal of Contemporary Research, 2(4): 132-142.

Roberts, R. (2014). “Gender, Adaptation and Authorship: Three Decades of The 
Woman in Black." Studies in Theatre and Performance 34 (2): 126-139. doi:10.1080/14682761.2014.910999.

Sipos, T. M. 2010. Horror Film Aesthetics: Creating the Visual Language of Fear. Jefferson, North Carolina: McFarland.

Tan, S., B. A. Smith, and K. L. O’Halloran. 2015. “Online Leadership Discourse in Higher Education: A Digital Multimodal Discourse Perspective.” Discourse \& Communication 9 (5): 559-584. doi:10.1177/1750481315600302.

The Woman in Black. By Stephen Mallatratt, directed by John Correll Jr., Main Street Theatre Company, Parlin, NJ, November 2011. Accessed 20 October 2015. https://www.youtube.com/watch?v=eGguw2d7UHc; https://www.youtube.com/watch?v=GLYLgk_7918

The Woman in Black. 1989. Directed by Herbert Wise. Performed by Adrian Rawlins. ITV Network, 1989. Film.

The Woman in Black. 2012. Directed by James Watkins. Performed by Daniel Radcliffe. Hammer Film Productions, 2012. Film.

van Leeuwen, T. 1999. Speech, Music, Sound. Houndsmills: Macmillan Press. Waller, G. A. 1985. "The Uses and the Pleasures of Horror." Quarterly Review of Film Studies 10 (3): 255-260. doi:10.1080/10509208509361268 